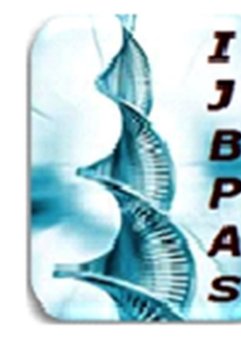

International Journal of Biology, Pharmacy and Allied Sciences (IJBPAS)

'A Bridge Betueen caboratory and QRendo'

Www.ijbas.com

\title{
ISOLATION, IDENTIFICATION AND ANTIBACTERIAL ACTIVITY OF HALOPHILIC ACTINOMYCETES FROM SAMBAI SALTPAN, RAMANATHAPURAM, INDIA
}

\author{
VIGNESHWARI $\mathbf{J}^{1}$ AND SENTHILKUMAR PK ${ }^{{ }^{*}}$ \\ Department of Microbiology, Annamalai University, Annamalai nagar-608002, Tamilnadu, \\ India
}

*Corresponding Author: Senthilkumar PK; E Mail: drpks1980@gmail.com

Received 22 ${ }^{\text {nd }}$ July 2021; Revised 25 ${ }^{\text {th }}$ Aug. 2021; Accepted $30^{\text {th }}$ Sept. 2021; Available online $1^{\text {st }}$ Nov. 2021

https://doi.org/10.31032/IJBPAS/2021/10.11.1072

ABSTRACT

Halophilic actinomycetes isolated from the saltpan soil samples of sambai saltpan,ramanathaburam,tamilnadu,india.SHA-1 strains are shows the best antagonistic and antibacterial activity against the Gram Positive- Stapylocoocus aureus, Stapylocoocus saprophyticus, Streptococcus pneumoniae, Enterococus faecalis, Enterobacter aerogens and Gram negative- Escherichia coli, Salmonella typhi, Klebsiella pneumoniae ,pseudomonas aeruginosa and serratia marcescens. The potential strains were confirmed genus level as Streptomyces $s p$ by morphological, physiological and biochemical identification. Morphological identification was done by gram staining shows filamentous branch structure and SEM analysis shows the $2 \mu \mathrm{m}$ in size. The exploration of new antibiotics are isolated from unexploted saline environments.

Keywords: Halophilic actinomycetes, Antagonistic activity, SEM

\section{INTRODUCTION}

Hypersaline habitats can be found throughout the salt mines and salt pans, with high salt concentrations. Salt pans, saline lakes, oceans, seas, and lagoons are examples of hypersaline ecosystems [1].
When compared to typical sea water salinity, hypersaline settings have a much higher salinity range. The evaporation of seawater causes the saltpan to form naturally. Solar salterns are used to make 
salts and have been found to be beneficial to Halophilic bacteria [2]. India is the world's fourth-largest producer of salt, with an annual output of 145 lakh tonnes. Salt is a mixture of two molecules, sodium $(\mathrm{Na}+)$ and chloride $(\mathrm{Cl})$, and it is one of the oldest chemicals. Extremophiles are organisms that live in severe environments and are classified as Piezophiles (pressure), Thermophiles (temperature), Pychrophiles (cold), Alkaiphiles/ Acidophiles (pH), and Halophiles (halophiles) (Salinity). Extremophiles are microbes that can survive under extremes of $\mathrm{pH}$, salinity, pressure, and radiation

Halophiles can only survive at high salt concentrations, and they can be classified according to how much salt they need to thrive. Salt tolerance $(\mathrm{Nacl})$ is divided into four categories: halotolerant $(0->1.0), \quad$ slight halophile $\quad(0->3.0)$, moderate halophile ( 0.4-3.5), and extreme halophile (0.4-3.5). (2.0-5.2) 1978-1989, Kushner (6). For halophilic microorganisms to survive, potassium chloride must accumulate in their cytoplasm. The term Halophil is derived from Greek and means "salt-loving microorganisms." These are all rich in potential product discovery. The halophile genes encode for salt tolerance, the ability to synthesise and absorb diverse compatible solutes, and the ability to grow in high saline conditions. Based on phenotypic characteristics, Bergeys manual of systematic Bacteriology $1^{\text {st }}$ edition divides actinomycetes into seven groups. Based on 16srRNA sequencing, the 2nd edition classifies the class, order, subclass, and faniles. Actinomycetes are unicellular, spore-forming filamentous, mycelialforming organisms with low $\mathrm{G}+\mathrm{C}$ content. Filamentous, spores, morphology, colours, and pigments are all used to classify and identify actinomycetes [3]. They are a type of fungus that is midway between bacteria and fungi [4].

Actinomycetes are morphologically range from filamentous fragments, Unicellular coccoid, rod coccoid and non branching mycelial forms. Mostly they are slow growing organism and powdery colonies appearance. Many actinomycetes mycelium extends substrate and forms condiospores, asexual spores and filamentous. Spores are located in a sporangium is called sporingiospores. The cell wall of actinomycetes is made up of peptidoglycan but its composition varied some isomeric forms, presence and absene of glycine in different groups of sugar molecules [5]. Actinomycetes is a major source of antibiotics, accounting for approximately $80 \%$ of all antibiotics used worldwide. In the past three decades, discoveries of new compounds have declined from soil derived 
actinomycetes For this reason, researchers have started focusing towards unexplored niches like marine sources, lagoons, lakes and saltpans. They are exciting novel sources of bioactive compounds with promising anti-microbial activity against pathogenic strains

Halophilic actinomycetes produced huge bioactive compounds include antiviral, anticancer, antifungal and antibacterial compounds. Most of the bioactive compounds synthesized the species are Streptomyces only because it's a ancient species and produce more than $80 \%$ of antibiotics production. The bioactive compounds are secreted by the Streptomyces, Arthrobacter, Frankia, and Micromonospora genera. Antimalarial, antiviral, anticancer, and antibacterial activities are all possible using biocompounds. The seventeenth [6-8]. Halophilic actinomycetes are secondary metabolised, described, and have chemical structures that can be exploited to create novel medicines. eighteen [9]. New halophilic actinomycetes have been pursuing novel neurotoxic, antiimiotic, antiviral, antibacterial, and cytotoxic compounds [10]. New antibiotics have been found as a result of some studies. Streptomyces species detect chinikomycin and lajollamycin, while halophilic actinomycetes strain detects novel antibiotics. The main objective of the present study to isolate and identification of the potential halophilic actinomycetes and check the antibacterial activity.

\section{MATERIALS AND METHODS}

\section{Collection and pretreatment of soil sample}

The salt pan soil samples were collected from geographical region Of Sambai salt pan $\left(9^{0} 30^{\prime} 59^{\prime}\right.$ 'N, $\left.78^{0} 54^{\prime} 222^{\prime \prime} \mathrm{E}\right)$ located in Ramanathaburam district,tamilnadu. These samples were collected at $10 \mathrm{~cm}$ depth of soil surface. The soil sample was collected at random in sterile Zip-lock cover and stored in a refrigerator for further use [11] Soil samples were air dried for one week at room temperature. The air dried sediment samples were grinded by using mortal pestle and passed through $\mathrm{mm}$ sieve filter to remove gravel and debris. The samples were pretreated with $\mathrm{CaCO}_{3}[\mathbf{1 2}]$.

\section{Isolation of halophilic actinomycetes}

The pretreated one gram soil sample was serially diluted with $9 \mathrm{ml}$ of sterile saline water up-to 10-5 dilutions. Then, $0.1 \mathrm{ml}$ aliquot of diluted samples was used for traditional spread plating with Actinomycetes isolation agar (AIA) supplemented with chloramphenicol and amphotericin $(100 \mu \mathrm{g} / \mathrm{mL})$ to avoid bacterial and fungal contamination respectively. The plates were incubated at $28^{\circ} \mathrm{C}$ and 
monitored periodically up to 7 days of incubation period [13]. The isolates were purified using quadrant streaking procedure and then maintained on Same medium 4 ${ }^{\circ} \mathrm{C}$. The isolates were maintained in their respective isolation media and salinity. The preservation of actinomycetes isolates were kept at $4^{\circ} \mathrm{C}$ and as stored with glycerol storage at $-80^{\circ} \mathrm{C}$.

\section{Sources of bacterial pathogens}

Bacterial pathogens such as Gram Positive- Stapylocoocus aureus, Stapylocoocus saprophyticus, Streptococcus pneumoniae, Enterococus faecalis, Enterobacter aerogens and Gram negative- Escherichia coli, Salmonella typhi, Klebsiella pneumoniae, pseudomonas aeruginosa, serratia marcescens were obtained from Metropolis healthcare private limited, Chennai, Tamilnadu. Pathogens were stored in nutrient agar agar slants at $4^{\circ} \mathrm{C}$ for further use.

\section{Preliminary antagonistic activity}

The isolated halophilic actinomycetes were screened for their antibacterial activity by using Cross-streak method against for bacterial pathogens. The actinomycetes were streaked on centre region of Starch Casein agar and incubated for 7 days. After the incubation, the bacterial pathogens were streaked on the sides of the plates and reincubate $37^{\circ} \mathrm{C}$ for $24 \mathrm{~h}$. Based on the presence or absence of inhibition zone the antimicrobial producing halophilic actinomycetes were selected for further studies [14].

\section{Extraction of cell free supernatant}

The potential actinomycetes strain SHA1 were inoculated into Starch casein broth and incubated at $28^{\circ} \mathrm{C}$ in a shaker at (120 rpm) for 7 days. After incubation, the broths were filtered through Whatman No. 1 filter paper. Then the filtrates were centrifuged separately at $10000 \mathrm{rpm}$ for 10 min to extract the supernatant. It was transferred aseptically into a screw capped bottles and stored at $4^{\circ} \mathrm{C}$ for further assay.

\section{Antibacterial activities of Cell free supernatant}

The antimicrobial activity of cell free supernatant were evaluated by agar well diffusion method. Pathogenic bacterial strains were inoculated in Nutrient broth and incubated overnight at $37 \mathrm{oC}$ for exponential growth of culture. Further the bacterial cultures were swabbed of Muller Hinton agar plates and make a well of 6mm. Different volumes viz., $25 \mu \mathrm{l}, 50 \mu \mathrm{l}$, $75 \mu \mathrm{l}$ and $100 \mu \mathrm{l}$ of cell free culture supernatant were loaded on the wells and incubated at $37^{\circ} \mathrm{C}$ for 24 hours. Finally the zone of inhibition was measured by antibiotic zone scale.

Phenotypic Characterization 
The identification of microbes on the basis of colony morphology. It is the basic step for identification. Colony morphology was recorded with respect to aerial colour, aerial mycelium, nature of colony, pigmentation and the isolates were observed under the microscope the light microscopy and Scanning electron microscopy. The powdery colonies are produced by actinomycetes. All the actinomycetes strains were subjected to Gram's staining and biochemical tests tests are used for genus level confirmation [15].

Cultural Charracteristics of

\section{Actinomycetes}

Morphological charracters and colour determination of isolates was studied on different media such as Yeast Malt extract agar, Oat meal agar, Starch casein agar, Inorganic Salts starch agar, Kennight agar, Actinomycetes agar and Glycerol aspargine agar medium was used [16].

\section{Effect of Temperature, $\mathrm{pH}$ and $\mathrm{NaCl}$}

The isolates were streaked at the starch casein agar medium, the plates were incubated at unique temperature tiers $\left(28^{\circ} \mathrm{c}, 30^{\circ} \mathrm{c}, 37^{\circ} \mathrm{c}, 40^{\circ} \mathrm{c}\right.$ and $\left.55^{\circ} \mathrm{c}\right)$ for 7 days (Saurav and Kannabiran, 2009). pH test was carried out on ISP2 media. $\mathrm{pH}$ was adjusted to different ranges of 5,6,7,8,9 and 10.The basal medium turned into organized, which have been supplemented with $\mathrm{NaCl} 20 \mathrm{~g}, 40 \mathrm{~g}, 60 \mathrm{~g}, 80 \mathrm{~g}$ and $100 \mathrm{~g}$ in line with litre. The medium was autoclaved and poured into the plates. Every plate turned into streaked with actinomycetes and incubated for 7-14 days. The tolerance limits of actinomycetes to nacl became determined and analyzed relatively, best after the period of incubation [15].

\section{Biochemical identification}

The biochemical characterization was carried out of the potential antagonistic actinomycetes. The biochemical tests are indole, methyl-red, Voges Proskauer test, Citrate utilization test, Catalase test, Urease test, Oxidase test, Starch hydrolysis, Nitrate reduction were performed for identifying genus level. All tests according to International Streptomycetes Project and Bergey's Manual of Systematic Bacteriology [16].

\section{Microscopic examination}

\section{Gram staining}

The actinomycetes culture smear was prepared on the clean glass slide. It allow to air dried and heat fixed. Heat fixed smear was flooded with crystal violet solution and allowed for one minute and again washed with water and flooded with mordant iodine solution and left for one minute. It was then drained and decolorized with $95 \%$ ethanol, washed gently in running water and counter stained for one minute with Safranin and washed with 
distilled water. The water drained smear was observed under microscope

\section{Light microscopy}

A cover slip culture technique for light microscopy. Actinomycetes culture plate was prepared and cover slip are placed at angle of 45 degree. The actinomycetes culture was released at the mycelium and coverslip. The plates were incubated at $28^{\circ} \mathrm{C}$ for 7 days. Afterwards, the cover slip were removed and observed under the microscope at high magnification. The spores, sporangia, aerial and mycelium were observed and noted.

\section{Scanning Electron Microscopy}

For scanning electron microscope the agar blocks containing the pure isolates of actinomycees cultivated on starch casein agar media supplemented with $5 \% \mathrm{NaCl}$ for 14 days at $28^{\circ} \mathrm{C}$ ) were fixed with the vapour of $1 \%$ osmium tetroxide and dried samples were sputter coated and viewed with scanning electron microscope

\section{RESULTS}

The four halophilic actinomycetes strain were isolated from the soil samples from sambai saltpan, Ramanathaburam District, Tamilnadu (Figure 1). All the isolates strains are go for checking the antagonistic activity against the Gram Positive- Stapylocoocus aureus, Stapylocoocus saprophyticus, Streptococcus pneumoniae, Enterococus faecalis,
Enterobacter aerogens and Gram negativeEscherichia coli ,Salmonella typhi, Klebsiella pneumoniae, pseudomonas aeruginosa, serratia marcescens. Among the four isolates, the isolate SHA-1 strain only showing good antagonistic activity (Table 1). The pure culture of SH1 strain is subcultured on SCA (Figure 2). The potential strain was characterized by phenotypic, and Biochemical identification test (Table 2). Furtherly the potential strain were optimized by cultural characters, different $\mathrm{pH}$, Temperature and $\mathrm{NaCl}$ concentration. The results are starch casein agar is the best media for growing halophilic actinomycetes (Table-3). The optimum temperature is $\left(28^{\circ} \mathrm{C}\right)$ and optimum $\mathrm{pH}$ level is 8 (Table 4). The potential strain SHA-1 supernatant are extracted and check the antibacterial activity against the bacterial pathogens by agar well diffusion method. The SHA-1 strain showed high zone of inhibition against the pathogens viz. Streptococcus pneumoniae $(30 \mathrm{~mm})$, Salmonella typhi (28mm) Stapylocoocus aureus (29mm), Stapylocoocus saprophyticus $(29 \mathrm{~mm})$, pseudomonas aeruginosa, (25 $\mathrm{mm})$, Escherichia coli (24mm), Klebsiella pneumoniae $(20 \mathrm{~mm})$, serratia marcescens (20mm) Enterococus faecalis $(16 \mathrm{~mm})$ and Enterobacter aerogens (14mm) (Table 5). In morphology the cover slip culture 
showing branching filamentous structure by

light microscopy and SEM analysis

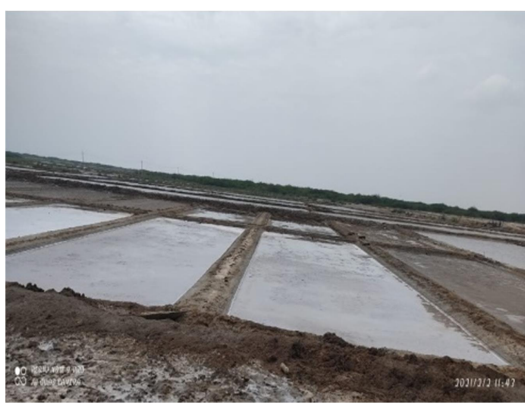

Figure 1: Sambai saltpan showing the spore-chain morphology size

\section{$2 \mu \mathrm{m}$ of SHA-3 strain (Figure 3).}

Table 1: Preliminary in vitro antagonistic activity

\begin{tabular}{|c|c|c|c|c|c|c|c|c|c|c|c|}
\hline \multirow[b]{2}{*}{$\begin{array}{l}\text { S. } \\
\text { No. }\end{array}$} & \multirow[b]{2}{*}{ Isolates } & \multicolumn{10}{|c|}{ Zone of inhibition (mm) } \\
\hline & & $\begin{array}{c}\text { s.aureu } \\
s\end{array}$ & $\begin{array}{c}\text { S.Pneumo } \\
\text { niae }\end{array}$ & $\begin{array}{c}\text { S.saprop } \\
\text { hyticus }\end{array}$ & $\begin{array}{c}E . \\
\text { fae } \\
\text { clis }\end{array}$ & $\begin{array}{c}\text { E.aer } \\
\text { ogen } \\
\quad s\end{array}$ & $\begin{array}{l}\text { K.pneu } \\
\text { moniae }\end{array}$ & $\begin{array}{c}\text { E.col } \\
i\end{array}$ & $\begin{array}{c}\text { p.aeurogi } \\
\text { nisa }\end{array}$ & S. marcescens & S.typhi \\
\hline 1 & SHA1 & ++ & ++ & ++ & + & + & + & + & + & + & ++ \\
\hline 2 & SHA2 & ++ & ++ & - & + & - & ++ & - & + & + & - \\
\hline 3 & SHA3 & - & - & + & + & - & - & - & + & - & - \\
\hline 4 & SH4 & + & - & + & - & - & + & - & - & - & ++ \\
\hline
\end{tabular}

-: No inhibition,+:moderate inhibition, ++ : high inhibition

Table 2: Biochemical identification of SHA1

\begin{tabular}{|c|c|c|}
\hline S. No. & BIOCHEMICAL TEST & SHA1 \\
\hline $\mathbf{1}$ & Indole & - \\
\hline $\mathbf{2}$ & Methyl Red & + \\
\hline $\mathbf{3}$ & Voges Proskauer test & - \\
\hline $\mathbf{4}$ & Citrate utilization test & + \\
\hline $\mathbf{5}$ & Catalase test & - \\
\hline $\mathbf{6}$ & Urease test & - \\
\hline $\mathbf{7}$ & Oxidase test & + \\
\hline $\mathbf{8}$ & Starch hydrolysis & + \\
\hline $\mathbf{9}$ & Nitrate reduction & + \\
\hline
\end{tabular}

-: No growth,+: Poor growth, ++: Moderate growth,+++: Good growth

Table 3: Culture characters of SHA1 on different culture media

\begin{tabular}{|c|c|c|c|}
\hline S. No. & Medium & Test & Properties \\
\hline 1. & Yeast malt extract agar(ISP-2) & SM AM & Whitish, pale greyish and brown \\
\hline 2. & Oatmeal agar (ISP-3) & AM & Whitish to chalk white \\
\hline 3. & Inorganic salt starch agar (ISP-4) & SM & Sandal white \\
\hline 4. & Glycerol asparagine agar (ISP-5) & AM & No growth \\
\hline 5. & Starch casein agar & AM & Whitish to pale sandy \\
\hline 6. & Actinomycetes isolation agar & AM & Light yellow \\
\hline 7. & Kennight's agar & AM & Pale yellow, brown \\
\hline
\end{tabular}

ISP: International Streptomyces Project; Pigmentation: Nil for all the media; AM: Aerial mycelium; SM: Substrate mycelium

Table 4: Physiological Charracterization of SHA1

\begin{tabular}{|c|c|c|c|c|c|}
\hline \multicolumn{2}{|c|}{ Growth temperature } & \multicolumn{2}{c|}{ Growth pH } & \multicolumn{2}{c|}{ NaCl concentration } \\
\hline $12^{\circ} \mathrm{C}$ & - & pH 4.0 & NaCl $2 \%$ & NaCl $4 \%$ & + \\
\hline $20^{\circ} \mathrm{C}$ & + & pH 5.0 & + & NaCl $6 \%$ & + \\
\hline $28^{\circ} \mathrm{C}$ & ++ & pH 6.0 & + & NaCl $8 \%$ & + \\
\hline $30^{\circ} \mathrm{C}$ & ++ & pH 7.0 & ++ & NaCl 10 & ++ \\
\hline $37^{\circ} \mathrm{C}$ & + & pH 8.0 & +++ & +++ \\
\hline
\end{tabular}

No growth,+: Poor growth, ++: Moderate growth,+++: Good growth 
Table 5: Antibacterial activity of cell free supernatant from SHA1

\begin{tabular}{|c|c|c|c|c|c|c|}
\hline \multirow[b]{2}{*}{ Pathogens } & \multicolumn{6}{|c|}{ Zone of inhibition (mm) } \\
\hline & $25 \mu l$ & $50 \mu \mathrm{l}$ & $75 \mu \mathrm{l}$ & $100 \mu \mathrm{l}$ & +ve Control & -ve Control \\
\hline Stapylococcus aureus & 20 & 25 & 30 & 29 & 32 & - \\
\hline Streptococci pneumonia & 18 & 20 & 25 & 30 & 36 & - \\
\hline Stapylocoocus saprophyticus & 10 & 16 & 18 & 29 & 31 & - \\
\hline Enterococcus faecalis & 8 & 10 & 13 & 16 & 30 & - \\
\hline Enterobacter aerogens & 9 & 11 & 12 & 14 & 27 & - \\
\hline Escherichia coli & 15 & 18 & 21 & 24 & 31 & - \\
\hline Salmonella typhi, & 17 & 22 & 26 & 28 & 33 & - \\
\hline Klebsiella pneumoniae & 16 & 18 & 19 & 20 & 30 & - \\
\hline pseudomonas aeruginosa & 21 & 23 & 24 & 25 & 28 & - \\
\hline serratia marcescens & 13 & 15 & 19 & 20 & 29 & - \\
\hline
\end{tabular}

Value represents mean $\pm \mathrm{SD} ; \mathrm{n}=3 \quad \mathrm{NZI}-$ No zone of inhibition

DISCUSSION

Demar et al., 2020 [17] isolate the Streptomyces $\mathrm{sp}$ from environments, located at corum province by dilution plate technique method using starch casein agar supplemented with $3 \%, 10 \%$ and $15 \%$ $\mathrm{NaCl}$ concentration. In this study the total of four halophilic actinomycetes isolated from sambai saltpan soil sample in ramanathaburam district, Tamilnadu, India. . Among them only one SHA-1 strain only showing antagonistic activity and antibacterial activity against the bacterial pathogens Stapylocoocus aureus, Stapylocoocus saprophyticus ,Streptococcus pneumoniae, Enterococus faecalis ,Enterobacter aerogens, Escherichia coli ,Salmonella typhi, Klebsiella pneumoniae ,pseudomonas aeruginosa, serratia marcescens by cross streaking method. Williams and Davies [18] identified the actinomycetes by colony morphology, color and pigmentation. Potential SHA-1 strain were recorded the chalky white color powdery colonies, filamentous hyphae structure was observed by cover slip method. The genus level identification of this SHA-1 strain are confirm the genus of Streptomyces $s p$. Biochemical characteristics of the strain were recorded and confirm the genus level. The optimum $\mathrm{pH}$ level is 8 , temperature $28^{\circ} \mathrm{C}, \mathrm{NaCl}$ concentration is $10 \%$ and the best cultural medium starch casein agar. Potential strain morphology were examined by scanning electron microscope observed $2 \mu \mathrm{m}$ in size.

\section{CONCLUSION}

Halophilic actinomycetes as a source for bioactive compounds. This study finding the halophilic actinomycetes Streptomyces $\mathrm{sp}$ is confirmed powerful secondary metabolite producers for producing novel drugs without side effects. However the unexplored ecological area yet to be investigated for rare halophilic actinomycetes.

\section{REFERENCES}

[1] Oren A. Halophilic microorganisms and their environments. Dordrecht, Boston: Kluwer Academic Publishers, 2002 
[2] Oren A. 2005. A hundred years of Dunaliella research: Saline Systems, 1: 1905-2005.

[3] Prescott, L.M., Harley, J.P., Klein, D.A. Microbiology 5th Edn. McGraw-Hill Higher Education, New York.2005

[4] Naikpatil, S. V. and J. L. Rathod,. Selective isolation and antimicrobial activity of rare actinomycetes from mangrove sediment of Karwar. $J$ Ecobiotechnol; 2013(10): 48 - 53

[5] Cao, L., Yun, W., Tang, S., Zhang, P., Mao, P., Jing, X., Wang, C., Lou, K. Biodiversity and enzyme screening of actinomycetes from Hami Lake, Wei Sheng Wu Xue Bao(2009) 49(3): 287-293.

[6] Mayer, A. M., A. D. Rodriguez, O. Taglialatela-Scafati and N. Fusetani, .marine compounds with antibactrial, antidiabetic, antifungal, anti-inflammatory, antiprotozoal, antituberculosis, and antiviral activities; affecting the immune and nervous systems, and other miscellaneous mechanisms of action. Mar. Drugs; 2013(11), 2510 -2573 .

[7] Dos Santos, A. O., E. A. Britta, E. M. Bianco, T. Ueda-Nakamura, B. P. Filho, R. C. Pereira 4-Aceto xydolastanedi terpene from the Brazilian brownalga Canistrocarpus cervicornis as antileish manialagent. Mar Drugs; 2011( 9) 2369 - 2383

[8] Cheng, S. Y., C. S. Hsue, G. H. Hwang, L. C. Tsai and S. C. Pei, Hourly oral miso prostol administration for terminating mid trimester pregnancies: a pilot study. Taiwan J Obstet Gynecol; 2010(49) $438-441$.

[9] Mincer, T. J., W. Fenical and P. R. Jensen, Culture dependent and culture independent diversity within the obligate marine actinomycete genus Salinispora. Appl Environ Microbiol; 2005 (71) 7019 - 7028.

[10] Singh LS, Baruah I, Bora TC Actinomycetes of Loktak habitat: isolation and screening for antimicrobial activities. Biotechnology, 2006 5(2): 217221.

[11] Roshan K, Tarafdar A, Saurav K, Ali S, Lone SA, Pattnaik S, Tyagi A, Biswas $\mathrm{K}$ and Mir A . Isolation and screening of bioactive compound from actinomycetes isolated from salt pan of marakanam district of the state Tamilnadu, India. Elixir Bio Technology 2013(61) 1682616831. 
[12] Seong C H, Choi JH, Baik KS. An improved selective isolation of rare actinomycetes from forest soil. J. of Microbiol, 2011(17) 2339.

[13] Ishita Chakraborty, Priyanka Redkar, Minki Munjal SR, Sathish Kumar and Bhaskara Rao KV. Isolation and characterization of pigment producing marine actinobacteria From mangrove soil and applications of bio-pigments. Der Pharmacia Lettre, 2015 7(4): 93-100.

[14] Velho-Pereira, S., Nandkumar, K., Screening of actinobacteria for antimicrobial activities by a modified "Cross-Streak" method. Nature Proceedings. 2012. 7, 116.

[15] Tresner HD, Hayes JA, Backns EJ: Differential tolerance of Streptomyces to sodium chloride as a taxonomic aid. Appl. Microbiol. 1968; 16: 1134- 1136.

[16] Shirling EB and Gottlieb D. Methods for characterization of Streptomycetes species. Int. J. Syst. Bac, 1996 (16) 313-340.

[17] Demet T. Isolation, phylogenetic analysis and antimicrobial activity of halophilic actinomycetes from different saline environments located near corum province Biologia, 2020.

[18] Williams, S.T., Davies, F.L., Use of a Scanning Electron Microscope for the Examination of Actinomycetes. J. Gen. Mkrobiol. 1967 (48) 171-177. 